\title{
RE-CONCEPTUALIZACIÓN DE LA SUBJETIVIDAD DESDE AMÉRICA LATINA
}

Floralba Aguilar Gordón *

Hablar de la subjetividad, y consecuentemente del sujeto, no ha sido una tarea nueva. Ha tenido y sigue teniendo una diversidad de enfoques y connotaciones, pero todas las acepciones consideran que la subjetividad está relacionada a un conjunto de actividades psico-sociales del sujeto.

Este artículo abordará brevemente las concepciones y los sentidos de la subjetividad, se considerará a la subjetividad desde la historia de la filosofía, desde la psicología, desde la pedagogía y desde la historia para luego determinar los procesos de subjetivización y proponer la necesidad de una re- conceptualización de la subjetividad desde América Latina.

Re-conceptualizar y re-construir el sentido y significado del sujeto y la subjetividad es el campo de acción que se propone el presente artículo.

\section{Concepciones de Subjetividad}

El concepto "subjetividad" es un término polisémico. Encontramos diversas acepciones acerca del mismo. A partir de la década de los sesenta, la mayoría de ellas

* Doctorado en Filosofía y Letras. Masterado en Educación Superior. Docente Universidad Politécnica Salesiana. 
considera que la subjetividad es de naturaleza social (tal como lo plantean Freud en su obra Psicología de las masas y análisis del Yo y Enrique Pichón Riviere, en sus obras Psicología de la vida cotidiana y en El Progreso grupal y cultural), ya que en la vida anímica del individuo, "el otro" cuenta con total regularidad, como modelo, como objeto, como auxiliar y como enemigo. El otro social siempre está presente en el horizonte de toda experiencia humana. De modo que el sujeto es relacionado y producido a la vez; todo lo que existe en él es producto de la interacción entre individuos, grupos y clases.

Se considera que la subjetividad se construye en una dimensión interaccional simbólica que incluye relaciones de poder, relaciones económicas, relaciones tecnológicas, en donde la subjetividad es al mismo tiempo singular y emergente, guarda relación entre la acción del productor y de lo producido. La subjetividad se constituye en las estructuras de vinculación que son al mismo tiempo autónomas e interdependientes. La subjetividad es un conjunto de vínculos, un sistema dinámico, abierto al mundo, está en construcción (Cfr. Pichón Riviere, P., 1996: 37).

Pichón Riviere concibe al sujeto en una doble dialéctica: intrasistémica e intersistémica, es decir que la subjetividad implica considerar tanto la interioridad como la exterioridad del sujeto.

La subjetividad implica una interrelación entre sujeto cognoscente y objeto cognoscible, en la cual, la importancia de cada uno de estos factores depende de la tendencia ideológica de los sujetos involucrados en el proceso gnoseológico. Así, por ejemplo, mientras los exponentes del idealismo presentaban al mundo como una construcción del sujeto cognoscente, como un contenido de conciencia, los representantes de corrientes opuestas, co- 
mo el realismo, (propio del pensamiento antiguo y medieval) consideraban que la realidad es independiente de la mente del sujeto o de la conciencia cognoscente, es decir, para el realismo, el sujeto cognoscente no construye la realidad que conoce.

El proceso de aprendizaje determina en el sujeto la conformación de esquemas referenciales ${ }^{1}$ que consolidan la subjetividad en base a experiencias, sensaciones, percepciones, imágenes y condiciones de existencia propias del sujeto.

Este esquema referencial es el que le permite al sujeto poseer modelos de sensibilidad, modos de pensar, sentir y hacer en el mundo y que marcan su cuerpo de determinada manera. Es en su tendencia a la repetición que va a ofrecer resistencia ante lo novedoso, ante los estímulos (ideas o experiencias) que lleven a desestructurarlo (Cfr. Pichón Riviere, 1996: 63).

El breve recorrido acerca de la subjetividad coloca al hombre latinoamericano frente al reto de repensarse como sujeto dinámico y en condiciones y realidades concretas (necesidad de pensarse, autoreconocerse y autovalorarse).

En perspectiva latinoamericana, el tema de la subjetividad remite directamente a la cualidad relacional con el contexto social, al tema de la alienación, a la enajenación, a la dependencia; en fin, a la necesidad de construir un sujeto social, crítico, reflexivo, proactivo, emprendedor, autónomo ${ }^{2}$ y protagonista de los cambios históricos.

Desde el ámbito latinoamericano, "ser sujeto" deberá entenderse como el acto autoafirmativo mediante el cual el sujeto se posiciona y apropia de su contexto para valorarlo y ejecutar sus acciones protagónicas, en otras palabras, la subjetividad latinoamericana estaría caracterizada por lo siguiente: la necesidad de autodetermina- 
ción contextual, la independencia en la diversidad, la apertura a alternativas múltiples, la responsabilidad y solidaridad social, el compromiso ético humano emancipatorio, la integración social en la diversidad y la contradicción, la dialéctica en la construcción social abajo-arriba, arriba-abajo, el empoderamiento para la autogestión social (Cfr. D Angelo, Ovidio, 2005: 9). Rasgos apropiados para lograr la adecuada construcción de una subjetividad autónoma e integradora.

\section{La subjetividad desde la historia de la filosofía}

Partiendo de una visión retrospectiva de la subjetividad en la historia de la filosofía, podríamos afirmar que el marcado cosmocentrismo distintivo de la filosofía antigua priorizó la existencia de la realidad objetiva expresada mediante un elemento físico, material (presocráticos) o expresada a través de un elemento inmaterial (ideas de Platón), pero de cualquier modo, la búsqueda de la primera causa objetiva de la realidad es lo que determinará las subsiguientes interpretaciones de lo real.

El cambio de orientación filosófica impuesto por los sofistas en sus investigaciones sobre el lenguaje, el ser humano y la sociedad; o la orientación práctica del saber con miras a la consecución de la felicidad del hombre propia de la filosofía helenística ${ }^{3}$, no alteró la predisposición a aceptar, "ingenuamente", la existencia de una realidad objetiva, independiente del ser humano que la piensa.

Por consiguiente, en la antigüedad, todo lo existente, incluido el pensamiento mismo, quedó supeditado a la objetividad y a la reflexión acerca del objeto.

El teocentrismo de la filosofía medieval demostró su interés en Dios. Los primeros siglos de nuestra era, 
la expansión del cristianismo y otras religiones dieron lugar a la aparición de otros modelos de felicidad o de "salvación individual", que compitieron con los modelos filosóficos ${ }^{4}$. El tema fundamental de reflexión medieval se restringió a la divinidad. La comprensión e interpretación del mundo, del hombre, de la sociedad quedaron subordinadas al conocimiento que se pueda obtener de lo divino. La fe entra en diálogo con la razón. Luego de la crisis de la Escolástica, la filosofía dejó de ser sierva de la teología; se logró la independencia de la razón.

El desarrollo del humanismo y de la filosofía renacentista, junto con la revolución copernicana, asociada al desarrollo de la Nueva Ciencia, impusieron nuevas formas de pensar, de sentir y de vivir.

El antropocentrismo de la filosofía moderna se asentó en el terreno de la subjetividad. Las dudas planteadas sobre la posibilidad de un conocimiento objetivo de la realidad, material o divina, hicieron del problema del conocimiento el punto de partida de la reflexión filosófica moderna. Se considera que la filosofía moderna pasa de la afirmación de una "subjetividad condicionada" a una "subjetividad desencadenada"; así, con Descartes, la substancia deja de ser fundamento de la verdad y su lugar es ocupado por el sujeto. Luego de la filosofía crítica de Kant, el Idealismo alemán, a través de Hegel, se convirtió en la corriente predominante en la Europa continental. Hegel traspasó los límites que Kant había puesto a la subjetividad humana y transformó el ego cogito cartesiano en el "sujeto absoluto".

En la época contemporánea, el existencialismo de Kierkegaard, el marxismo y el vitalismo de Nietzsche fueron una reacción al idealismo hegeliano ${ }^{5}$.

En Nietzsche, la subjetividad llega a su máximo grado de desarrollo. El sujeto destrona al Dios cristiano, a 
su metafísica y a su moral, logra una libertad absoluta para encarar la tarea de dar el mismo sentido y valor a las cosas.

La tecnocracia y el nihilismo son la expresión de la subjetividad desencadenada y de la muerte de la metafísica tradicional. La técnica permitió el dominio del mundo a cambio de ocultar nuestro ser y alterar nuestra relación con las cosas (Cfr. Academia de Ciencias Luventicus, 2003-2009: 1).

Marx, Nietzsche y Freud, los "maestros de la sospecha”, ponen en duda la realidad creada por el sujeto consciente y que Descartes propuso para la creación del edificio del conocimiento.

Para Marx, el sujeto se halla inmerso en una situación en la que las relaciones de producción y las fuerzas de trabajo, propias del capitalismo, lo convierten en un ser enajenado, un ser que no se pertenece a sí mismo. Para Freud, el sujeto es producto de lo inconsciente, cuyos contenidos afloran en los sueños, y para Nietzsche, el sujeto se halla inmerso en una caja de valores tradicionalmente adquiridos, es decir, impuestos por una autoridad moral ajena al propio sujeto.

El desarrollo de las ciencias sometió a la filosofía a fuertes críticas por parte de los defensores del pensamiento científico, que consideran a la ciencia como un paradigma de conocimiento verdadero.

En los últimos cincuenta años del siglo XX, la cuestión del sujeto entró en crisis, se vivió un sistemático intento de disolución del sujeto. Una buena parte de la filosofía contemporánea vivió y filosofó en contra del yo unitario surgido como consecuencia de las reflexiones filosóficas propias del siglo XVII.

En definitiva, en la historia de la filosofía moderna y contemporánea encontramos que la reflexión filosófica acerca del sujeto y de la subjetividad pasa por tres fases: fundamento, disolución y replanteamiento. 
Sin embargo, se podría afirmar que no toda la filosofía del siglo XX dio lugar a la cuestión del sujeto; así, en el campo de la epistemología (constituida a comienzos del siglo XX) se visualiza una explícita exclusión del sujeto ${ }^{6}$. De este modo, la filosofía de las ciencias había de ser exclusivamente un análisis de las lógicas de las teorías científicas, de su lenguaje, de su validación, de su racionalidad interna. Este estilo epistemológico, con su pretensión de objetividad, optó por no considerar a los sujetos como productores de las teorías científicas, eligió no tener en cuenta los procesos psicológicos, sociales, culturales o históricos implicados en la emergencia de dichas teorías científicas, ni tampoco considerar las implicancias éticas y políticas de las prácticas científicas. Fue necesaria la reflexión de Bachelard a partir de los años treinta y, tres décadas más tarde, los desarrollos de Kuhn, Lakatos y Feyerabend, entre otros, para que pudiera darse un lugar al sujeto, a la sociedad y a la historia en la epistemología.

En la actualidad, particularmente a partir de los epistemólogos de la complejidad, resulta insoslayable tratar la cuestión del sujeto ${ }^{7}$. Hay tendencia a considerar una armonía entre sujeto y objeto, entre mente y mundo, entre el yo y las cosas porque la realidad es compleja, dinámica, integra al yo y a sus circunstancias; integra a lo concreto y a lo abstracto; integra a lo real y a lo ideal; en fin, las cosas no son independientes del sujeto y de los procesos de subjetividad (y viceversa).

\section{La subjetividad desde la psicología}

Lo referente al sujeto y la subjetividad no apareció en la psicología como producto de la modernidad (como sucedió en la filosofía).

La modernidad caracterizó a la psicología por una metodolatría (Danziger, 1990) que sustituyó al sujeto 
por conjuntos de variables y comportamientos a ser observados y/o medidos (González, 2000: 9).

La construcción de la subjetividad o de conceptos relacionados a lo subjetivo, en psicología, aparecen por primera vez con el nacimiento del pensamiento dialéctico procedente del marxismo. Los fundadores del enfoque histórico-cultural integran por primera vez la idea de un sujeto subjetivamente constituido mediante la incorporación de elementos como afecto - cognición; lo social y lo individual; aspectos que se integran a una representación del individuo como sujeto de sus procesos psicológicos. Es una idea clara en Vigotsky y en Rubinstein ${ }^{8}$. El sujeto al que se refiere Vygotsky es el sujeto personal subjetivado de la acción social.

Por otra parte, en el psicoanálisis freudiano es difícil reconocer la figura del sujeto como protagonista activo en los espacios de la vida social. A pesar de que Freud presentó un sujeto dotado de razón, éste no es concebido al estilo del sujeto de la modernidad, sino en el sentido de que en sus actos y en su lenguaje puede aparecer su transformación ${ }^{9}$ (González, Fernando, 2000: 18).

El sujeto presentado por Freud está subordinado a lo psíquico, al inconsciente, es un sujeto determinado por su interioridad dinámica, afectiva y contradictoria.

Un aporte interesante sobre el objeto de nuestro estudio fue el realizado por Lacan, al sustituir el fenómeno subjetivo (que reconoce la emoción y el sujeto individual como constitutivos de la subjetividad) por lo simbólico y el discurso.

Revisando las tendencias actuales en la construcción teórica del sujeto y la subjetividad encontramos que, actualmente, la cuestión del sujeto se encuentra supeditada dentro del espacio de lo simbólico, del análisis del discurso, del enfoque teórico y metodológico que van 
configurando el pensamiento del construccionismo social que prioriza el orden simbólico de los discursos y de lenguaje sobre los que se organizan todos los procesos sociales y personales (Cfr. Mitjáns, 2008: 5-6).

Las tendencias de la psicología actual critican la institucionalización de la ciencia, consideran que el afecto es una dimensión constitutiva del hombre, que encuentra formas específicas de organización en diferentes niveles de la existencia humana, todos los cuales se relacionan entre sí y se configuran en diversas formas en los procesos de subjetivación.

\section{La subjetividad desde la pedagogía}

La dimensión de la subjetividad se encuentra presente en todo el proceso y los componentes pedagógicos. La subjetividad contribuye para la comprensión de los procesos educativos y conlleva una diversidad de enfoques y contribuciones.

Si consideramos que la educación es una práctica social humana, ella implica la participación de personas, para lo cual se auxilia en la psicología; sin pretender hacer una psicologización de la educación, la subjetividad en el campo pedagógico contribuye para la estructuración de líneas de investigación, para la aplicación de la didáctica, para la orientación metodológica, para el establecimiento de criterios de evaluación.

El análisis de las configuraciones subjetivas y objetivas que intervienen en el aprendizaje determina sentidos diversos de comprender, interpretar y de actuar en el mundo. El sentido subjetivo del rendimiento académico, la deficiencia y/o el desarrollo del aprendizaje son determinantes en el proceso educativo. El docente y el estudiante como principales sujetos involucrados en el pro- 
ceso educativo deconstruyen, construyen y reconstruyen el conocimiento de manera permanente.

Respecto a la subjetividad pedagógica, revisando algunas de las ideas de Michael Foucault encontramos que la educación es una liberación, la pedagogía una forma de producir la libertad, y tanto la educación como la pedagogía han de preocuparse no de lo disciplinar o producir saber, sino de transformar sujetos. No producir sujetos, sino llevarlos a procesos de transformación de su propia subjetividad" (Foucault, 1994: 65).

Se puede visualizar que todos son aspectos efectivos para determinar la función de la educación y la pedagogía en América Latina; constituyen referentes para la reconstrucción de los sujetos involucrados en las mencionadas prácticas, las cuales implican a sujetos mediados por el conocimiento y situados en un espacio físico determinado (aula-institución educativa), en una estructura conceptual específica (sistema educativo) y en un ámbito macro (sistema social), todo atravesado por tres ejes fundamentales: "poder-saber, teoría-práctica, vida cotidiana y situacionalidad histórica" (Wohning, 2005: 1) que involucra un adecuado manejo disciplinar, multidisciplinar y transdisciplinar de carácter teórico-práctico.

La práctica pedagógica en el contexto latinoamericano involucra una diversidad de procesos analíticos, críticos y reflexivos determinados por la necesidad de repensar el contexto; conocimiento teórico práctico de los fundamentos de las asignaturas; manejo metodológico y didáctico para interpretar, reconceptualizar y reconstruir procesos, teorías, prácticas y enfoques educativos específicos.

La práctica pedagógica involucra prácticas sociales y culturales que tienen al sujeto (social) como referente. La práctica pedagógica tiende a configurar un-suje- 
to-que-está-siendo en relación a otros; un sujeto que requiere darse forma, un sujeto que se encuentra en una situación específica, pero que sabe que es inconcluso y dinámico, un sujeto guiado por el thymos (deseo de reconocimiento).

De allí que la subjetividad pedagógica es proceso y producto. Es proceso en cuanto se encuentra determinada por el deseo de llegar-a-ser, un aspecto propio del sujeto singular; y, es producto en cuanto a la relación implícita y explícita entre el "querer aprender" (individual) y "poder de enseñar" (social).

La construcción de la subjetividad pedagógica requiere de diferentes procesos dialécticamente articulados por los cuales se llega a ser sujetos histórico- sociomorales. Constituirse como sujeto implica una actitud y una actividad teórica-práctica frente a los diversos problemas del mundo y de la vida misma.

Si consideramos (como Foucault) que el proceso de subjetivación acontece gracias a cuatro pliegues: el de la sustancia o la parte material de nosotros mismos, el de los modos de sujeción o el de poder; el de la actividad autoformadora o el saber en tanto relación de lo verdadero con nuestro ser; y el del afuera o finalidad, según el cual el sujeto espera algo de sí; el pliegue singular, un adentro del pensamiento coextensivo con el afuera que se va doblando en procesos variables históricamente, se irá configurando diversos modos de subjetivación.

De tal manera que cuando hay pliegue hay subjetividad, se instaura un modo en que el sujeto hace la experiencia del sí mismo en un juego de verdad en el que está en relación consigo mismo (Foucault, 1991: 76).

El quehacer educativo debe ser repensado permanentemente considerando sus fines y objetivos. La educación actual deberá responder a las necesidades del 
contexto, debe ser una educación de carácter endógena (subjetiva) que no se preocupa solamente de los contenidos ni de los efectos con relación al comportamiento y actitudes, sino que se preocupe por la interacción dialéctica entre las personas y su realidad; deberá ser una educación que permita el desarrollo de sus capacidades intelectuales y de su conciencia social. Será una educación que reconoce en el estudiante la capacidad de razonamiento, participación y elaboración conceptual.

La educación como proceso subjetivo implica valorar las subjetividades, intersubjetividades, la interioridad, la corporeidad con sus propios procesos de construcción. La subjetividad en la educación se despliega en diversos escenarios vitales donde el sujeto creador de realidades múltiples debe ser asumido a partir de su pluralidad constituyente; es decir que es importante que el educador se reconozca a sí mismo en su subjetividad y reflexione sobre su forma de ser, de estar, de sentir y de relacionarse con otros, en diferentes contextos y permitir que el estudiante también se asuma en su interior y en ese mirarse; lo cognitivo adquiera significado individual dentro de la experiencia colectiva.

\section{La subjetividad desde la historia}

La idea de subjetividad supone pensar que cada situación histórica genera su propio concepto práctico de hombre ${ }^{10}$. Es decir, se genera a partir de prácticas específicas, intervenciones, marcas corporales, enunciados y discursos. Es necesario considerar que la adquisición de conocimientos se realiza a partir de determinados contextos culturales que regulan y establecen diferentes modos de legitimar los aprendizajes. 
Conocer las características de la época en que vivimos, teniendo en cuenta la incidencia en la subjetividad educativa, constituye un instrumento de valor para diseñar nuevas propuestas pedagógicas que permitan la utilización de recursos para alojar al sujeto que allí se forma.

En general, la idea del sujeto aparece con fuerza en las ciencias sociales. En los últimos años daría la impresión de que se está viviendo el paso de la muerte al rescate del sujeto; así, encontramos que el sociólogo Alain Touraine presenta la idea de un sujeto subjetivado, de un sujeto que no esta "sujetado" de forma absoluta; un sujeto que tiene la capacidad generadora de subjetividad que le permite asumir posiciones emancipatorias frente a los órdenes exteriores de cualquier tipo, que pretenden negarlo y manipularlo (Cfr. Touraine, 1999: 111).

Desde el punto de vista histórico, se podría considerar a la subjetividad como la búsqueda de sentido y como una categoría social. Como búsqueda de sentido en la medida que es el sujeto quien construye y analiza el discurso histórico; el sujeto tiende a subordinarse a la lengua y a la historia como sostenía Lacan, a su vez, la categoría de sentido es esencial para la comprensión del sujeto y de la subjetividad en el proceso histórico. El sentido subjetivo es comprendido como el conjunto de emociones que se integran en los diferentes procesos y momentos de la existencia del sujeto, apareciendo constituidos en una cualidad que es parte de la emocionalidad que caracteriza al sujeto en esa zona de la experiencia.

Toda producción humana está articulada en un sistema de sentidos que expresa la forma en que las necesidades del sujeto se organizan en el curso de su relación con el otro y con el mundo. La organización de estas necesidades tiene un momento histórico y un momento ac- 
tual, los que son inseparables en la organización del sentido subjetivo de toda experiencia. En este sentido, el sujeto aparece como sujeto de necesidad, su vínculo con el mundo está subjetivado por las necesidades que se configuran dentro de este proceso de relación, las que son inseparables de las necesidades definidas por sus configuraciones motivacionales, procesos esenciales de la subjetivación (Cfr. Ibíd: 132).

La subjetividad entendida como categoría social en la medida que la individualidad por sí sola no puede explicar la praxis histórico-social, la búsqueda de construcciones teóricas capaces de dar cuenta de la complejidad de los sujetos sociales, eliminó al sujeto individual, así como a los procesos de constitución de la subjetividad individual, los que pasaron a ser definidos de forma directa desde lo social.

La naturaleza del fenómeno subjetivo se da simultáneamente a nivel interno y a nivel externo aunque se encuentren mediados por la historia específica de cada uno de ellos, de manera que la subjetividad individual y las posiciones de cada sujeto están siempre conectadas de forma directa con su historia, la que aparece constituida en configuraciones diferentes de sentido y significación.

El sujeto se caracteriza por un estado permanente de producción emocional como parte esencial de sus procesos de subjetivación, como un principio constitutivo esencial del sujeto; lo emocional está integrado a dimensiones diferentes propias de los sistemas de relaciones humanas, así como a los procesos de significación. Los sentidos son precisamente las formas particulares de esa emocionalidad en los diferentes procesos de relación y zonas de experiencia del sujeto.

El sujeto que como latinoamericanos asumimos es un sujeto constituido social e históricamente, 
tanto en la historia de las formaciones discursivas constitutivas de su propia condición como también en su historia personal, donde la constitución de sentidos está estrechamente comprometida con la condición singular desde la cual este sujeto ha recorrido la historia de su existencia individual. Así, el sentido de sus procesos de subjetivación está comprometido de forma simultánea con los discursos que atraviesan los distintos espacios sociales en que vive, que son parte de su lenguaje y se subjetivizan de diferentes formas en los diferentes contextos de su acción, como con sus configuraciones subjetivas personales, que sintetizan en cada uno de los momentos actuales de su expresión.

El sujeto tiene una capacidad generativa asociada a los procesos de subjetivación, que representa un momento constitutivo de sus procesos de sentido y significación (Cfr. Touraine, 1999: 103).

En fin, el sujeto es congruente porque se encuentra consigo mismo y es capaz de luchar y sentir por lo que cree, dimensión sin la cual lo nuevo, el cambio serían imposibles.

El sujeto es pensamiento además de lenguaje, posición muy bien desarrollada por Vygotsky; el sujeto se reafirma a través del ejercicio de su pensamiento, que es el instrumento creativo a través del cual penetra en el lenguaje, lo crea, lo usa y, simultáneamente, se expresa a través de él más allá de su conciencia. La cuestión es comprender esos dos momentos de la relación sujeto-lenguaje, el sujeto como productor, creador y crítico del lenguaje, y el sujeto subordinado a estructuras discursivas, las cuales puede quebrar a través de las posiciones que asuma, aunque el proceso de ruptura no sea lineal a su intencionalidad consciente (Cfr. Touraine, 1999: 67). 
Para comprender la subjetividad histórica latinoamericana, considero necesario rescatar la "razón vital" y la "razón histórica" de Ortega y Gasset para reconceptualizar al sujeto histórico social desde nuestras propias circunstancias reales y concretas; para analizar y comprender la vida misma del sujeto hacedor de su historia; para entender la vida como un saberse y comprenderse a sí mismo, para tomar conciencia de nuestra existencia y del no-yo del mundo circundante, de las personas y de las cosas que nos rodean; para encontrarnos y habérnoslas en el mundo como ingrediente de la vida, como escenario de participación humana; para considerar que la vida es un proyecto donde el hombre está-siendo.

La razón vital conduce a la razón histórica porque la vida es esencialmente cambio e historia. La razón histórica tiene como objetivo permitirnos comprender la realidad humana a partir de su construcción histórica y de las categorías de la vida. Con la razón histórica podemos superar las limitaciones de la razón fisico-matemática, formal y abstracta propuesta en la modernidad. La realidad humana es temporalidad e historia. El mundo humano consta de sentidos y es la razón histórica la que puede contribuir para comprender los sentidos de la existencia humana, y para ello se ha de referir a dimensiones del vivir como los sentimientos, valoraciones y proyectos del individuo o colectividad que queramos estudiar, y a las categorías, creencias y esquemas mentales con los que damos un sentido a nuestra vida y nos enfrentamos al reto de la existencia (Cfr. Ortega y Gasset: 135).

Así, el individuo es el producto de una sociedad existente, bajo una forma concreta. Esta definición permite retomar el postulado marxista según el cual se llega a lo concreto por lo abstracto; similar proceso es el que tenemos que emprender en América Latina para lograr la re- 
construcción mental de lo concreto generando procesos de autocreación y transformación mediante la praxis histórico social. Al transformar la realidad objetiva, la naturaleza y la sociedad, el hombre transforma las condiciones de su existencia y, por consiguiente, se transforma a sí mismo como especie (Cfr. Schaf, 1966: 31).

El educador no puede estar ajeno a estos problemas, así como al cuestionamiento acerca de los resultados, posibilidades y limitaciones de su práctica social. Al no mediar un proceso de reflexión, tanto sobre la influencia de la representación en la práctica como en el sentido y soporte de dichas teorías, la propia práctica sigue reproduciendo esquemas que muchas veces contradicen los valores e ideales del mismo docente. Tanto en lo individual como en lo social, en lo biológico como en lo psicológico, en lo material como en lo espiritual, la transmisión de la cultura es la más importante función de la educación.

\section{Procesos de subjetivización necesarios para América Latina}

Los procesos de subjetivización en América Latina deberán estar orientados desde la actividad pedagógica.

Es preciso interrogarse, reflexionar y hacer una hermenéutica, por y desde el presente mismo, considerado el campo de la historia y de la historicidad.

Es indispensable interpretar los condicionamientos históricos, sociales, simbólicos y económicos que en la práctica docente permitirá explicar la dinámica de la sociedad y de sus protagonistas.

La tarea a emprender considerará la historia de nuestra subjetividad, una ontología del presente que se realiza sobre tres ejes: en relación con la verdad que nos 
constituye como sujetos de conocimiento; en relación con el campo de poder en el cual nos constituimos como sujetos que actúan sobre otros; en relación con la ética según nos constituimos en sujetos morales (Cfr. Wohning, 2005: 8).

Desde esta perspectiva, el proceso educativo en América Latina debería tender a la concientización de la necesidad de autorreflexión para lograr una verdadera transformación de los sujetos considerando el pliegue del saber en donde el pedagogo y el estudiante son sujetos con capacidad para identificar problemas; pensar y repensar; regular, redireccionar y modificar procesos; buscar alternativas de solución y modificar las formas de pensar, sentir, actuar y de estar-en-el-mundo.

Se debería re-significar diferentes categorías conceptuales propias del quehacer pedagógico con miras a legitimizar la educación y lograr una mejor comprensión de los procesos de enseñanza-aprendizaje fundamentados en las teorías emergentes que establecen la necesidad de considerar como eje fundamental al educando, sus intereses y su contexto, en contraposición de la educación tradicional caracterizada por la mera transmisión lineal y homogénea del conocimiento (visto como absoluto, concluido y verdadero) en la que el rol pasivo, de escucha y de ejercitación del estudiante mecanizan los saberes e impiden el involucramiento de procesos de transformación en la práctica docente.

Es preciso proporcionar estrategias que permitan el desarrollo del pensamiento crítico-creativo en el estudiante para optimizar su desenvolvimiento en el mundo. El estudiante deberá desarrollar la capacidad para establecer conexiones entre el conocimiento socialmente elaborado y su sentido y significación para la realidad individual y social. 
La educación es la mejor estrategia para la adquisición del capital cultural de nuestros países; es la herramienta más adecuada para la construcción del modelo socio-histórico-cultural que involucre procesos de objetivación en relación dialéctica en los cuales se articulan las tres funciones básicas de la representación: la función cognitiva de integración de la novedad, la función de interpretación de la realidad y la función de orientación de las conductas y las relaciones sociales que determinan una nueva forma de ser y de ver el mundo .

El proceso de constitución de la subjetividad requiere reconocer la necesidad de una síntesis global que explique a la sociedad humana como una totalidad estructurada y, por otro, considerar que las causas no pueden reducirse a un problema de motivos ya que toda causa está acompañada de un conjunto que hace a las condiciones en las que ocurre un fenómeno (Cfr. Bloch, 1982: 46).

Considerar los objetivos de la educación de acuerdo al contexto, el objetivo de la educación para la era planetaria es fortalecer las condiciones de posibilidad de la emergencia de una sociedad-mundo compuesta por ciudadanos protagonistas, consciente y críticamente comprometidos en la construcción de una civilización planetaria (Morin, 2005: 89).

Al estilo de Bourdieu, es necesario modificar las estructuras cognitivas que se encuentran constituidas en la relación dialéctica entre el habitus ${ }^{11}$ y el campo; entonces la realidad social existe dos veces, en las cosas y en los cerebros, en los campos y en los habitus, en el exterior y en el interior de los agentes. El concepto de habitus permite articular lo individual y lo social, las estructuras internas de la subjetividad y las estructuras objetivas que constituyen las condiciones materiales de la existencia humana. Al 
mismo tiempo este concepto permite comprender que las estructuras subjetivas y objetivas, lejos de ser extrañas por naturaleza, son dos estados de la misma realidad, de la misma historia social que se inscribe a su vez en los cuerpos y en las cosas (Cfr. Bourdieu, 1997: 85).

Es decir que los modos de conformación de la subjetividad involucran la constitución de habitus (conjunto de disposiciones duraderas e interiorizadas históricamente por el individuo y que determinan la práctica concreta) y el campo (integrado por un conjunto de relaciones históricas objetivas depositadas en los cuerpos individuales y ancladas en ciertas formas de poder). Bourdieu propone la idea de que la correspondencia entre las estructuras sociales y las mentales limita la percepción política del mundo social y cumple funciones eminentemente políticas, ya que los sistemas simbólicos no son meros instrumentos de conocimiento sino que son también instrumentos de dominación, por su capacidad de integración cognoscitiva, promueven la integración social a un orden arbitrario. La reproducción de la creencia se basa en la perpetuación del acuerdo entre las estructuras mentales y las estructuras objetivas.

Desde la pedagogía, el concepto de habitus permite integrar tres dimensiones de la educación: la social, la histórica y la política, tanto en relación con el educador como con los educandos, en la teoría como en la práctica docente, en el vínculo pedagógico como en la efectividad de la transmisión cultural.

En el campo pedagógico, las nociones de campo y habitus abren una posibilidad para interpretar la constitución histórica de las representaciones acerca del transmitir de los docentes y se estima posible incidir en una conceptualización que permita avanzar en la definición de estrategias de universalización del conocimiento elaborado a través de un vínculo pedagógico democrático. 
La determinación de las estructuras objetivas en la constitución de la objetividad tiene límites, así por ejemplo, el concepto de habitus no promueve el optimismo pedagógico; por el contrario, permite comprender cómo los procesos de socialización dejan marcas en la subjetividad que sólo podrán ser atenuadas por una pedagogía racional que apunte a compensar las diferencias de origen de los individuos.

Bourdieu asigna al concepto de habitus un gran poder generador; si bien la capacidad de engendrar prácticas se haya constituido históricamente, no es reductible por completo a sus condiciones de producción. Diferencia así este concepto de la noción de costumbre, entendiéndola como repetitiva, mecánica, automática, más reproductora que productora.

Pero no hay que confundir el habitus (como sistema de esquemas de percepción, de pensamiento, de apreciación y de acción) con las prácticas que contribuye a producir (esto es, representaciones, opiniones, valoraciones, obras culturales, etcétera). El habitus es el principio de producción y organización de las prácticas, pero opiniones y estilos diferentes pueden ser generados a partir de esquemas genéticos idénticos (Cfr. Ibíd: 32).

De acuerdo a esta perspectiva, existen dos modos típicos de constitución de los habitus: la educación primera o aprendizaje por familiarización (espontánea, implícita, infiltrada en todas las prácticas sociales en que participa el niño) y el trabajo pedagógico racional (la acción escolar). Para Bourdieu ${ }^{12}$, el aprendizaje por familiarización y las pedagogías racionales constituyen dos modos de adquisición de la cultura; la competencia cultural de cada individuo va a quedar marcada por su origen y a definir modos particulares de relación con la cultura. 
Así, interpretar la constitución histórica y social que configura las representaciones acerca de la transmisión de la cultura en los docentes, propiciar la reflexión conjunta sobre los fines y potencialidades de la educación, promueve objetivos teóricos-prácticos, políticos y éticos.

\section{Re-conceptualización del sujeto y de la subjetividad para la construcción del conocimiento}

A través del tiempo han proliferado innumerables intentos de presentación teórica de un sujeto universal, abstracto, formal, dogmático, cerrado y sustentado en principios ontológicos fundadores con los que la ruptura o el cuestionamiento era una tarea imposible.

Superar la noción del sujeto univocista y eurocéntrico implica:

- Apartarnos de las concepciones abstractas, universalistas, cosificadoras, objetivizadoras y despersonalizadoras que han negado nuestra condición de sujetos históricos y se han impuesto a través del tiempo.

- Rescatar en nuestras vivencias culturales y praxis cotidianas la singularidad que quedó encubierta bajo diferentes etiquetas totalizantes.

- Instaurar el diálogo como condición real de los procesos de subjetivación.

- Valorar la cultura popular y autoreconocernos como valiosos.

- Recuperar el sentimiento asociado a la praxis cotidiana individual y colectiva.

- Recuperar el derecho a pensar por nosotros mismos y a tener un espacio propio que no se agota en los deberes impuestos. 
- Construir un sujeto que busca, conoce y piensa.

- Considerar que el sujeto construye y transforma la realidad.

- Configurar una mente estratégica basada en la identificación de la problemática histórica, en la superación de la mentalidad metafísica, en la ejecución de un giro existencial estratégico fundamentado, según Samuel Guerra, en siete momentos: de la mente, de la razón, de la voluntad, del espíritu, de la solidaridad, de la interculturalidad, de la trascendencia con el propósito de alcanzar una mente maestra que nos permita ser nosotros mismos (Cfr. Guerra, 2009: 52-57).

- Reeducar nuestra mente para poder integrar lo teórico y lo práctico, lo objetivo y lo subjetivo; la planificación y el resultado (Cfr. Ibíd: 111-129).

Re-conceptualizar a la subjetividad desde América Latina significa:

- Comprender al sujeto como proceso generador de subjetivación.

- Comprender a la subjetividad desde una perspectiva histórico-cultural que está indisolublemente asociada a la idea del sujeto ${ }^{13}$.

- Comprender que el diálogo es la organización dentro de un nuevo espacio de sentidos y significados de varios sujetos constituidos en historias diferentes, que son capaces de generar un espacio en común que tolera la expresión de las diferencias y, a su vez, es un momento en la transformación de aquéllas ${ }^{14}$.

- Pensar y dilucidar los mecanismos favorables para una visibilización, re-construcción y re-va- 
lorización de lo latinoamericano (Cfr. Guerra, 2009: 14).

- Construir una sabiduría propia con miras a lograr la descolonización de nuestra subjetividad, nuestra condición de sujetos individuales y colectivos mediante diversos procesos de aprendizaje para re-descubrirnos, re-constituirnos, revalorarnos (Cfr. Ibíd.: 35).

- Desarrollar competencias de la razón intuitiva, de la razón cognitiva, de la razón dialéctica, de la voluntad, emocionales, del espíritu, éticas y cívicas para reivindicarnos y revalorizarnos a nosotros mismos con ayuda del redireccionamiento del sistema y de los procesos educativos (Cfr. Ibíd: 59-63).

- Utilizar un método dialógico o analéctico como proponía Enrique Dussel.

\section{Notas}

1 Es el conjunto de conocimientos, de actitudes que cada uno de nosotros tiene en su mente y con el cual trabaja en relación con el mundo y consigo mismo" (Pichón Riviere; Aplicaciones de la Psicoterapia de Grupo, 1957) y en Técnica de los Grupos Operativos, 1960). Conjunto de experiencias, conocimientos y afectos con los que el individuo piensa y hace.

2 Desde las corrientes psicológicas, el tema de la autonomía del individuo constituye un constructo sistémico integrado por procesos de autoexpresión, autoregulación, autodeterminación, autoactualización que se construyen en relación de interacción con los otros significativos a través de la formación de la identidad personal mediante las elaboraciones del autoconcepto, la autoestima (D Angelo, Ovidio, 2005: 6).

3 El estoicismo y el epicureísmo colocaron a la ética en el vértice del saber.

4 Frente a la inicial hostilidad hacia la filosofía manifestada por algunos de los primeros padres apologistas cristianos, sus continuado- 
res encontrarán en la filosofía (a partir del neoplatonismo de Plotino) un instrumento útil para combatir otras religiones o sistemas filosóficos y para comprender, o intentar comprender, los misterios revelados. Surge de ahí una asociación entre filosofía y religión, que puso las bases de la futura filosofía medieval.

5 Consagró la identificación del yo trascendental kantiano con el Dios del cristianismo.

6 El primer movimiento neopositivista de los Círculos de Viena, Berlín y Praga, así como la posterior filosofía analítica y las ideas de Popper, se centran en el "contexto de justificación" desechando como no pertinente el "contexto de descubrimiento".

7 Cfr. Wohning, Érica, 2005. Práctica, formación y subjetividad pedagógica. Una reflexión pedagógica. Facultad de Ciencias Humanas. San Luis, Argentina, pp. 18-19.

8 a Cfr. González, Fernando, "El sujeto y la subjetividad: algunos de los dilemas actuales de estudio". III Conferencia de Investigación SocioCultural. Sao Paulo, pp. 10-12.

9 Es concebida dentro del campo de análisis, donde la expresión del sujeto y de sus actos adquieren sentido solamente en el proceso terapéutico (Cfr. González, Fernando, 2000: 18).

10 Marx, en su sexta tesis sobre Feuerbach, decía que la esencia humana no es una abstracción inherente al individuo aislado sino que es, en su realidad, el conjunto de las relaciones sociales: la esencia del hombre iguala al conjunto de las relaciones sociales. Desde el materialismo histórico no es la conciencia de los hombres lo que determina su ser social, sino que la estructura de las relaciones sociales, de las relaciones de producción, determinan la conciencia, sentimientos y pensamientos del hombre. En este sentido, las relaciones sociales crean al individuo. El hombre real y concreto es un producto integramente social (Cfr. Schaff, 1966: 71).

11 Como producto y productor de las estructuras, permite la mediación entre las estructuras objetivas y las prácticas que realizan los agentes; como un sistema de disposiciones durables y transferibles que funciona como una matriz de percepciones, apreciaciones y acciones en las que integra todas las experiencias pasadas. Permite considerar la dimensión simbólica como mediación entre los elementos materiales y los elementos ideales de la vida social. (Cfr. Bourdieu, 1997).

12 Existen dos formas básicas de adquisición del capital cultural: la pedagogía familiar y la pedagogía racional. Asigna a esta última una función compensatoria de las desigualdades producidas por el 
origen social y cultural. Lo social presenta una doble existencia: se expresa tanto en las estructuras objetivas (estructuras independientes de la conciencia y de la voluntad de los agentes individuales, grupales, clases o sectores) como en las subjetividades (esquemas de percepción, de pensamiento y de acción que constituyen socialmente la subjetividad). Sustituye la noción de sociedad por los conceptos de espacio social y campo. Pensar en términos de campo significa pensar en términos de relaciones, lo real es relacional, lo que existe en el mundo social son relaciones, no interacciones o vínculos intersubjetivos entre agentes, sino relaciones objetivas que existen independientemente de la conciencia y la voluntad individuales (Cfr. ibíd.).

13 El sujeto es un sujeto portador de una subjetividad que expresa su historia personal en una síntesis de sentidos y significados que tiene como forma de organización la personalidad. La personalidad, al igual que el sujeto, representa una instancia generadora de sentidos, los cuales son inevitables dentro del contexto de acción del sujeto (González, Fernando, 2000: 14).

14 Cfr. ibíd.

\section{Bibliografía}

ARENAS, Luis:

2002 Identidad y Subjetividad: materiales para una historia de la filosofía moderna. Madrid: Editorial Biblioteca Nueva.

BLOCH, M.:

1982 Introducción a la historia. Brevarios. Argentina: Fondo de Cultura Económica.

BOURDIEU, Pierre:

1983 Campo de poder y campo intelectual. Buenos Aires: Folios Ediciones.

BOURDIEU, Pierre:

1997 Capital cultural, escuela y espacio social. México: Siglo Veintiuno.

BOURDIEU, Pierre:

1997 Razones prácticas. Sobre la teoría de la acción. Barcelona: Anagrama. 
D'ANGELO, Ovidio:

2005 Autonomía integradora y transformación social: el desafío ético emancipatorio de la complejidad. La Habana: Editorial Acuario.

FOUCAULT, Michael:

1994 Hermenéutica de sujeto. Madrid: Las Edic.de la Piqueta.

FOUCAULT, Michael:

1991 Tecnologías del yo. Barcelona: Ediciones Paidós, I.C.E./U.A.B.

FREUD, Sigmund:

1921 Psicología de las Masas y Análisis del Yo. Obras Completas. Ed. Amorrortu.

GONZÁLEZ REY, Fernando Luis:

1997 Epistemología Cualitativa y Subjetividad. Sao Paulo: EDUC.

GUERRA, Samuel:

2009 La emergencia del Espíritu. Ejercicios Espirituales antiimperialistas. Quito.

GUERRA, Samuel:

2009 Conócete a ti mismo. Filosofía del Cambio Existencial. Quito.

MITJANS MARTÍNEZ, Albertina:

2008 La Psicología en la transformación educativa. Subjetividad, complejidad y educación. México, Psicología para América Latina, N. 13.

MORÍN, Edgar:

2005 Educar en la era planetaria. Quito: Editorial Ecuador, Grupo Santillana. S.A.

ORTEGA Y GASSET, José:

1983 La Razón Histórica. Obras Completas. Madrid: Alianza Editorial, Vol. XII.

PICHÓN RIVIERE, E.:

1996 Psicología de la vida cotidiana. Ed. Nueva Visión.

PICHÓN RIVIERE, E.:

1996 El proceso grupal. Ed. Nueva Visión.

SCHAFF, Adam:

1964 La filosofía del hombre. Argentina: Editorial Lautaro.

VARIOS AUTORES

2006 La presencia de la subjetividad del maestro en el ejercicio de su práctica. Cauca: Editorial Luz.

WOHNING, Erica:

2005 Práctica, formación y subjetividad pedagógica. Una reflexión pedagógica. San Luis, Argentina: Facultad de Ciencias Humanas. 


\section{Bibliografía de Internet}

\section{ACADEMIA DE CIENCIAS LUVENTICUS}

2003-2009 "La historia de La filosofía según Heidegger”. Rosario. Argentina:http://www.luventicus.org/artículos/03U017/heidegger.htm

GONZÁLEZ REY, Fernando Luis:

2000 "El sujeto y la subjetividad: algunos de los dilemas actuales de estudio". III Conferencia de Investigación Socio-Cultural. Sao Paulo, Brasil: http://www.fae.unicamp.br/ br2000/trabs/1520.doc 